\title{
LEITURA DOS ESTEREÓTIPOS DA MULHER NEGRA BRASILEIRA EM "VIAJE AL OTRO BRASIL"
}

\author{
READING OF THE STEREOTYPES OF BLACK BRAZILIAN \\ WOMEN IN "VIAJE AL OTRO BRASIL"
}

Ruan Fellipe Munhoz*

\begin{abstract}
Resumo: Este artigo expõe uma leitura do relato Viaje al otro Brasil, publicado em 2002 pelo espanhol Javier Nart. Nessa obra, o viajante apresenta uma visão (ou revisão) do Brasil a partir do seu deslocamento por parte do centro-oeste, norte e nordeste. Nossa intenção é trabalhar especificamente com a imagem que esse estrangeiro constrói da mulher negra brasileira, tendo em vista que na maioria das vezes ela é representada como objeto de apreciação e deleite. Diante dessa problemática, discutimos o papel dos estereótipos na produção dos preconceitos e na manutenção do poder hegemônico. Para tanto, trabalhamos, fundamentalmente, com a contribuição de Souza (2004) para a questão da formação da imagem; a construção do discurso imperial pelos pressupostos de Said (2007) e Pratt (1999); a teoria dos estereótipos desenvolvida por Bhabha (1991) e também com as divisões sociais que geram discriminação com base em Ahmad (2002), Bonnici 2007) e van Dijk (2008).
\end{abstract}

Palavras-chave: Relato de viagens. Javier Nart. Estereótipo. Mulher negra.

Abstract: This article presents an analysis of the report Viaje al otro Brasil, published in 2002 by the Spanish author Javier Nart. In this work, the traveler shows a view (or review) of Brazil as he moves through part of the Center-West, North and Northeast regions. We intend to work specifically with the image that this foreigner builds upon the Brazilian black woman, since most of the times she is depicted as an object of appreciation and delight. Before this issue, we discuss which is the role of stereotypes in developing prejudices and maintaining hegemonic power. For this purpose, we employ, fundamentally, the contribution of Souza (2014) concerning image formation, the construction of imperial discourse as presupposed by Said (2007) and Pratt (1999), the theory of stereotypes developed by Bhabha (1991) and also the social divisions that generate discrimination based on Ahmad (2002), Bonnici (2007) and van Dijk (2008).

Keywords: Travel report. Javier Nart. Stereotype. Black woman.

\section{Introdução}

Viaje al otro Brasil: Del Mato Grosso a la Amazonia y al Nordeste Atlántico ${ }^{1}$ (2002) é um relato de viagens publicado pelo espanhol Javier Nart, que, além de escritor, é advogado, antigo correspondente de guerra, fotógrafo e atualmente cumpre mandato de Deputado do Parlamento Europeu. Apresentada em primeira pessoa, essa narrativa retrata o deslocamento de quarenta dias realizado pelo viajante, com início no município de Bonito, Mato Grosso do Sul, e término na ilha de Fernando de Noronha, arquipélago situado no estado de Pernambuco.

É importante destacar que a referida obra serviu também como base para a dissertação intitulada "O viajante e sua bagagem: imagens do Brasil e dos brasileiros (re)produzidas por dois espanhóis no início do novo milênio" (2019), apresentada pelo

\footnotetext{
* Doutorando em Estudos Literários pela Universidade Estadual de Maringá (UEM). Contato: ruan_munhoz@hotmail.com

${ }^{1}$ Não existe uma versão da obra em língua portuguesa, por esse motivo todas as traduções citadas neste trabalho são de nossa responsabilidade.
} 
autor ao programa de Pós-Graduação em Letras da Universidade Estadual de Maringá (UEM). O objetivo do citado trabalho foi discutir as imagens do Brasil construídas por viajantes espanhóis, destacando que essas construções imagéticas se constituem de representações ideológicas e se configuram como uma estratégia de dominação social e hierarquização cultural.

No caso deste artigo, apresentamos uma análise das imagens construídas por Javier Nart sobre as mulheres brasileiras, principalmente as mulheres negras, em três trechos específicos da produção literária, pequeno recorte que nos permite pensar alguns dos estereótipos reproduzidos pelo viajante espanhol. Em síntese, realizamos essa leitura com o intuito de contribuir com a possível desconstrução da imagem de mulher utilitária, conduzindo a uma maior compreensão da cultura na qual o autor da obra escolhida se insere, visando à representação da problemática produzida pelo narrador e a diferença cultural, social e racial estabelecida entre o indivíduo que observa e os indivíduos observados, para, consequentemente, refletir brevemente sobre questões relacionadas aos preconceitos e à identidade.

Para dinamizar o processo, trabalhamos a criação da imagem pela mente humana, partindo dos pressupostos de Souza (2004). Aliado a isso, discutimos as questões levantadas por Said (2007) e Pratt (1999) a respeito da formatação do olhar imperial, e também a produção de estereótipos, com base na proposta de Bhabha (1991). Esse percurso nos permite realizar uma análise a respeito da formação ideológica presente nas imagens discursivas desenvolvidas pelo viajante, indicando também as potenciais consequências dessas construções para a sociedade por ele observada.

Em um segundo momento, baseados nas discussões promovidas por Ahmad (2002), buscamos informações para entender a divisão proposta para os países em primeiro, segundo e terceiro mundo, concluindo que essa não é uma prática construída somente com intuito econômico, mas também como dominação das elites sobre os países considerados subdesenvolvidos.

Em seguida, partimos para a análise do relato de viagens utilizado como pano de fundo para este trabalho, enfatizando a forma como o homem, viajante, europeu, inserido em um contexto colonizador, observa e reproduz as imagens estereotípicas da mulher negra brasileira, a partir da sua posição privilegiada e de seu discurso que apresenta de maneira evidente ou sutil o seu lugar no mundo.

\section{0 processo de formação da imagem}

Os significados para tudo o que existe na Terra não são estáveis, por esse motivo há a necessidade de organizar os pensamentos e as vivências, buscando delimitar e estabelecer alguma ordem nessa instabilidade universal. $\mathrm{O}$ ser humano, para entender $\mathrm{o}$ mundo e tudo o que nele existe, dedica-se à tarefa de ordenar as sensações, para, em seguida, reconhecê-las e classificá-las (SOUZA, 2004). Essas sensações são reações nervosas promovidas pelos órgãos sensoriais do indivíduo em contato com o mundo exterior. É necessário lembrar que toda produção de significado apresenta limitações e subjetividades, justamente porque a realidade não se mostra de forma objetiva aos nossos olhos, olfato, paladar, tato e audição: 
maneira isolada. Ao contrário, sabe-se que este perfume é de uma rosa, que aquele ruído é da buzina de um carro que passa na rua, que esta luz é da lâmpada de seu quarto de trabalho. Estas sensações têm, assim, um caráter subjetivo e um valor relativo, pois não nos revelam os referentes tal como na realidade são, mas como eles são para nós (SOUZA, 2004, p. 94).

Portanto, quando se interpreta determinado referente, precisamos ter a ideia antecipada de que não mais o percebemos o referente em si, mas uma imagem subjetivada pelas nossas sensações, um referente contextualizado que passa por todo o processo analítico dessas sensações, encontra significados, sentimentos e percepções adquiridas com o decorrer da vida, funde-se a elementos de ordem sociais e culturais, para, finalmente, produzir uma interpretação coerente e verossímil da situação na qual o indivíduo se encontra.

A representação resulta desse processo de objetivação das sensações. Todas as informações adquiridas através dos cinco sentidos, associadas às informações arquivadas anteriormente na memória, são utilizadas para fazer com que o indivíduo perceba o objeto em análise e reconstrua uma imagem a partir desse processo de espelhamento:

\begin{abstract}
A imagem seria, portanto, a reviviscência ou a representação de uma sensação/percepção ou de um conjunto de sensações/percepções, que se encontram arquivadas na memória, e que, portanto, acontece na ausência do objeto que os provocou. A imagem seria, assim, uma configuração simbólica do real, efetuada no âmbito do cérebro, passível de ser mediatizada por um código (com todas as suas implicações). A imagem seria, portanto, uma forma de mimese, não se considerando aqui mimese em seu sentido tradicional unívoco de cópia fiel, mas ampliando-lhe o espectro conceitual para todas as representações possíveis que, afinal, são tentativas de tradução, quer de realidades exteriores quer de realidades interiores, pois estes dois tipos de realidades estão intrinsecamente interligados (SOUZA, 2004, p. 84).
\end{abstract}

Todas as produções que criaram, viveram e acreditaram os nossos antepassados e que também nós criamos, vivemos e acreditamos não podem ser comprovadas e instauradas como verdadeiras e irrefutáveis. Tudo é discutível, passível de subjetivação e de desconfiança, inclusive o discurso científico, porque as palavras não são utilizadas apenas para simbolizar as referências, elas também indicam as emoções, os humores, o estado de espírito de quem as produziu. Dessa forma, as referências não podem ser significadas apenas pelo que são, mas também deve ser levado em consideração o fato de serem produzidas em contextos específicos. Em suma, a mimese está em todos os produtos sociais que se constituem de referências do mundo, de imagens:

A mimese não é um fenômeno estático, mas um processo bastante flexível e plástico, pois na verdade está presente sempre que se tenta entender a realidade e exprimi-la. Há mimese tanto no discurso da história, da filosofia, etc., quanto no discurso literário, desde a prosa até a poesia. A mimese atravessa todo o imaginário do indivíduo (SOUZA, 2004, p. 103).

Pensando na mimese presente no discurso literário, começamos a refletir sobre o relato de viagens, gênero definido por Carrizo Rueda (2008) como o texto em que se apresentam memórias e informações sobre as experiências vividas através de deslocamentos físicos e psicológicos, desenvolvido, por esse motivo, como um produto 
híbrido entre o documental e os recursos atribuídos à literariedade. Considerando essa característica dual, precisamos indicar a dificuldade de reconhecer imediatamente os textos dessa categoria, tendo em vista que tudo o que é observado passa pelo crivo do observador, tudo o que é transmitido é representação e não uma realidade objetiva e concreta.

Toda produção de conhecimento nas ciências humanas requer o envolvimento do autor como sujeito inserido em determinado contexto social e cultural. Quando um indivíduo chega a um país estrangeiro, ele o estuda a partir da sua realidade pessoal, do seu corolário, aproximando-se primeiramente como estrangeiro e depois como indivíduo. Isso significa que, de forma obscura, o sujeito traz consigo a história, além de interesses e objetivos que não são individuais, mas construídos coletivamente.

No âmbito da filosofia, o pensamento e visão a que fazemos referência podem ser chamados genericamente de Orientalismo. Nesse sentido, Edward Said (2007) define o termo como uma instituição que, autorizada a discutir, analisar, lidar com temas relacionados ao Oriente, fortalece "afirmações a seu respeito, descrevendo-o, ensinandoo, colonizando-o, governando-o: em suma, o Orientalismo como um estilo ocidental para dominar, reestruturar e ter autoridade sobre o Oriente" (SAID, 2007, p. 29). Cerceada a liberdade e o discernimento para agir de acordo com seus princípios e filosofia, os países pertencentes a esse bloco não fixo que engloba o chamado Oriente são levados a agir de acordo com os interesses do Ocidente.

Sobre a utilização dos termos "Oriente" e "Ocidente" para dividir o globo, precisamos considerar que essa oposição não é natural, não é separada somente por aspectos geográficos e culturais, mas desenvolvidas e sustentadas pelos homens ocidentais:

\begin{abstract}
Seria incorreto acreditar que o Oriente foi criado - ou, como digo, "orientalizado" - e acreditar que tais coisas acontecem simplesmente como uma necessidade da imaginação. A relação entre o Ocidente e o Oriente é uma relação de poder, de dominação, de graus variáveis de uma hegemonia complexa (...). O Oriente não foi orientalizado só porque se descobriu que era "oriental" em todos aqueles aspectos considerados lugares-comuns por um europeu comum do século XIX, mas também porque poderia ser - isto é, submeteu-se a ser - transformado em oriental (SAID, 2007, p. 32).
\end{abstract}

Essa divisão se estabelece como uma forma de dominação imperial do Ocidente sobre o Oriente, aplicada de forma determinista nos discursos correntes e em objetos artísticos e culturais que penetram instituições, como escola, família, sindicatos, templos religiosos, exército, polícia, promovendo a reprodução mecânica, entrando no inconsciente dos seres humanos, tornando-se norma, desenvolvendo-se como verdade:

Portanto, o Orientalismo não é um simples tema ou campo político refletido passivamente pela cultura, pela erudição ou pelas instituições; nem é uma grande e difusa coletânea de textos sobre o Oriente; nem é representativo ou expressivo de alguma execrável trama imperialista "ocidental" para oprimir o mundo "oriental". É antes a distribuição de consciência geopolítica em textos estéticos, eruditos, econômicos, sociológicos, históricos e filológicos; é a elaboração não só de uma distinção geográfica básica (o mundo é composto por duas metades desiguais, o Oriente e o Ocidente), mas também de toda uma série de "interesses" que, por meios como a descoberta erudita, a reconstrução filológica, a análise psicológica, a descrição paisagística e 
sociológica, o Orientalismo não só cria, mas igualmente mantém; é, mais do que expressa, uma certa vontade ou intenção de compreender, em alguns casos controlar, manipular e até incorporar o que é um mundo manifestamente diferente (ou alternativo e novo); é sobretudo um discurso que não está absolutamente em relação correspondente direta com o poder político ao natural, mas antes é produzido e existe num intercâmbio desigual com vários tipos de poder (SAID, 2007, p. 40).

É importante observar que o intercâmbio desigual entre esses dois grupos gera a imposição e, consequentemente, a construção da identidade do dominado, mas também promove a construção do dominador pela relação com o "outro". Nessa perspectiva, Pratt (1999) desenvolve o conceito de "zonas de contato", definido por ela como "espaços sociais onde culturas díspares se encontram, se chocam, se entrelaçam uma com a outra, frequentemente em relações extremamente assimétricas de dominação e subordinação" (PRATT, 1999, p. 27).

Essa posição autoritária é construída e disseminada de forma persuasiva, manifestando-se como cânone, como discurso hegemônico e dignificado como verdadeiro. Isso ocorre de forma impositiva e violenta, tendo como objetivo a dominação que, no mínimo, constrói de forma coercitiva uma "teia de racismo, estereótipos culturais, imperialismo político, ideologia desumanizadora que reprime" (SAID, 2007, p. 59). Os estereótipos asseguram a perpetuação de imagens convenientes ao emissor, imagens essas que são repetidas até que sejam transformadas em caricatas. Nesse contexto, o nativo e todas as suas práticas são retratados com base em um discurso racista proveniente da ciência colonial que exalta suas diferenças e potenciais distúrbios físicos e mentais, a partir de aspectos da superfície física, tais como a tonalidade da pele e a estatura.

Reconhecer o estereótipo é importante para compreender as imagens como positivas ou negativas, exercício fundamental para repensar a forma como as diferenças interferem nas relações interpessoais, muitas vezes pautadas em um conjunto de preconceitos que evidenciam as práticas de hierarquização cultural e racial, rompendo, dessa forma, o pacto com o discurso colonial que "se concentra em construir o colonizado como população de tipo degenerado, tendo como base uma origem racial para justificar a conquista e estabelecer sistemas administrativos e culturais" (BHABHA, 1991, p.184).

2 A teoria dos três mundos: implicações para a sociedade

A expressão "Terceiro Mundo" surgiu no ano de 1952, período em que o mundo voltava suas atenções para a Guerra Fria. Em meio a esse contexto conflituoso, a mídia ocidental se interessava menos pelas realidades regionais e mais pelos embates entre Estados Unidos e União Soviética. Essas relações promoveram a divisão tripartite do mundo, sendo que o denominado "Primeiro Mundo" era composto pelos Estados Unidos, que detinham poder militar com alcance global; o "Segundo Mundo" compreendia os países aliados ao bloco comunista, ligados à União Soviética, que estavam, naquele momento, em decadência quanto ao poder econômico e militar; e o "Terceiro Mundo" foi direcionado a todos os países que não estavam alinhados militarmente a essas duas divisões estabelecidas anteriormente (AHMAD, 2002).

Diante dessa tentativa de homogeneizar diferentes realidades, parece correto afirmar que "o mundo não se divide em binário monolítico; é um modo hierarquicamente 
estruturado" (AHMAD, 2002, p. 194). Essa hierarquia pode se concretizar dentro de um mesmo território, excluindo a ideia fantasiosa de um "Terceiro Mundo" unificado, tendo em vista que esse caráter separatista, extremamente preconceituoso, é necessário para definir um grupo de pessoas que detêm algum tipo de poder, seja político, financeiro, militar e/ou cultural, com o intuito de manter o poder colonial, ao mesmo tempo em que os separa daqueles que sofrem os efeitos de tal poder:

O terceiro mundo, para onde uma multidão de povos e lugares é jogada indiscriminadamente, geograficamente consiste nas nações-estados da América Latina, Caribe, África, sudoeste asiático e sul da Ásia, a China e a Oceania. Outros povos como os ameríndios, os índios estadunidenses, os negros, os hispânicos, os asiáticos, os aborígines australianos e os maoris neozelandeses, os emigrantes africanos e árabes na Europa, muitos dos quais ainda mantêm laços estreitos com povos do assim chamado Terceiro Mundo geográfico, podem ser definidos por esse rótulo (MOHANTY, 1991, apud BONNICI, 2005, p. 66).

De forma geral, o que se apresenta é uma divisão imperialista que evidencia a relação de poder, pois de um lado se encontra o grupo dominador, detentor de privilégios e de reconhecida riqueza cultural; enquanto do lado oposto está o "outro", definido como exótico, primitivo, selvagem e não desenvolvido. Essa separação indica que o processo não é apenas econômico, mas também essencialmente político, definindo qual é a sociedade merecedora do status de superioridades no que confere as questões sociais e de raça.

A propagação da superioridade racial, branca por excelência, faz com que se crie esse estereótipo em oposição aos povos colonizados, de maioria negra, ou, sendo mais exato, não-brancos. No caso específico do Brasil, a abolição da escravatura que ocorreu somente no fim do século XIX não colocou fim ao processo de colonização, já que, ainda hoje, os europeus brancos continuam sendo o grupo étnico-racial dominante, impondo suas ideias e seus ideais ao Brasil e a toda América Latina, o que gera formas de dominação social, econômica e cultural pelas elites citadas:

\footnotetext{
A ubiquidade do "racismo europeu" no mundo é certamente a consequência histórica de séculos de colonialismo europeu, mas isso não implica que a pessoas "brancas" sejam essencialmente racistas, pois o fato é que há muitas pessoas brancas lutando contra o racismo. Nesse sistema de dominação, os não europeus (Outros) foram sistematicamente segregados e tratados como inferiores, uma ideologia que serviu como legitimação da escravidão, da exploração e marginalização (VAN DIJK, 2008, p. 11).
}

Essas questões de conflito racial e hierarquia social evidenciam uma separação racista entre os indivíduos. As justificativas dadas para tal ato vão desde o receio da degeneração racial, até questões de poder político e comerciais. A consequência dessa manifestação é a construção de sociedades marginalizadas, inseridas em classes inferiores em comparação com a sociedade central.

Acrescido a isso, devemos pensar na representação das mulheres nesse chamado "Terceiro Mundo", uma vez que entendemos que o discurso do colonizador interpela homens e mulheres de formas diferentes, o que resulta nessa dupla colonização para elas. Nesse contexto, as mulheres são atingidas pelo poder colonial e pela dominação do patriarcado. Em outras palavras, como sujeitos pós-coloniais, elas são inferiorizadas 
tanto pelas questões que concernem à raça, quanto ao gênero (BONNICI, 2007), situação que faz com que sofram diversos níveis de subordinação e subalternidade em relação ao homem-colonizador-europeu.

\section{A mulher negra aos olhos do estrangeiro}

A obra que serve como pano de fundo para este artigo é produzida a partir do trajeto feito pelo autor-narrador por parte do centro-oeste, norte e nordeste brasileiro. As imagens são apresentadas pelo viés do exótico, merecendo destaque os aspectos naturais, a fauna, a flora, os seres humanos e características do cotidiano que são estranhas aos olhos desse estrangeiro, aspectos que evidenciam as diferenças culturais estabelecidas entre o visitante e o visitado.

É necessário indicar que a literatura pode criar, suportar ou ainda alterar as imagens estabelecidas ideologicamente sobre as identidades de gênero. $\mathrm{O}$ fato de a obra ser construída de uma representação da realidade perpetua a ilusão de que o que é transmitido é algo natural, real ou verdadeiro. A partir dessa premissa, estudamos algumas imagens femininas construídas pelo olhar masculino, europeu e colonizador de Javier Nart (MUNHOZ, 2019). Nesse contexto, as mulheres são retratadas de acordo com os discursos sociais e as imagens se configuram pela tradução do que é visto por ele somado ao seu referencial pessoal.

É sabido que a imagem da mulher negra brasileira sempre foi concebida com base em algumas construções estereotípicas específicas, o que resulta na sua subrepresentação, "inclusive em relação ao homem negro, quando retratada, a tendência geral é de reproduzir os papeis estereotipados a muito reservados no discurso público brasileiro, particularmente o de mulata hipersensualizada" (SILVA; ROSEMBERG, 2012, p. 84), imagem que remonta ao período da escravatura, quando o corpo negro estava vinculado às diversas necessidades do macho senhor, inclusive a sexual.

Apresentando dados concretos a partir de pesquisas sobre a representação do indivíduo nos diversos meios de veiculação em massas de informação, Silva e Rosemberg (2012) concluem que a população negra é sub-representada pelos meios de comunicação e as questões relativas às desigualdades sociais são silenciadas, o que "exerce um duplo papel: o de negar os processos de discriminação racial, buscando ocultar a racialização das relações sociais, ao mesmo tempo em que propõe uma homogeneidade cultural ao "brasileiro"' (SILVA; ROSEMBERG, 2012, p. 82). A consequência desse ato é a representação do branco como espécie "natural" e suas características universais dispostas como norma para a humanidade. Por fim, o último aspecto ressaltado parece justificar os pontos assinalados anteriormente, justamente pelo fato do estereótipo desvalorizar um grupo social em oposição a outro:

A estereotipia na representação do homem e da mulher negra, adulto ou criança, é recorrentemente assinalada pelos estudos nas diversas mídias (...). A estereotipia foi particularmente notada na associação do negro com criminalidade em jornais, literatura e cinema; no desempenho de funções socialmente desvalorizadas na televisão, literatura infanto juvenil e livros didáticos; na exploração de estereótipos de "mulata", "sambista", "malandro" e "jogador de futebol" na literatura, publicidade impressa e televisiva, e no cinema (SILVA; ROSEMBERG, 2012, p. 82). 
Essa pesquisa, realizada entre 1987 e 2002, apresenta avanço limitado se comparado à realidade atual. Mesmo com o possível aumento na representação midiática da população negra, percebemos que ela permanece ainda em patamares inferiores à dos brancos, já que a representação continua sendo construída a partir de estereótipos, ou seja, com base na percepção que os brancos têm dos negros. A posição em questão parece sintetizar o que encontramos na literatura aqui analisada, já que ela dispõe de um narrador branco-europeu que constrói a imagem de um grupo do qual ele não faz parte, algo que poderia acontecer se essa voz compreendesse os seus privilégios.

Voltando o olhar para a obra literária propriamente dita, o primeiro estereótipo salientado por nós é o da mulher que encontra o seu espaço e sua serventia nos trabalhos domésticos. Essa imagem, retomada também dos tempos da escravatura, coloca a mulher negra em posição de total subalternidade em relação ao homem, seja ele patrão ou marido, sendo que essas duas classificações não são totalmente opostas, se pensadas a partir das relações de poder assumidas dentro de um espaço.

Nesse contexto, chama a nossa atenção a descrição de uma mulher, cujas características físicas superlativas são ressaltadas, juntamente com o potencial e força para o trabalho doméstico. Essa imagem remonta às imagens típicas da negra serviçal:

Havíamos nos alojado no hotel Djamila. Seus proprietários eram uma amável e serviçal negra gordíssima, casada com um palestino-brasileiro cuja atividade se reduzia a contemplar seus domínios desde uma poltrona na recepção, deixando as tarefas ingratas de gestão a cargo de sua ativíssima esposa: recepcionista, cozinheira, camareira, faxineira, etc., tudo em uma ${ }^{2}$ (NART, 2002, p. 23).

Apesar da aparente caracterização positiva da personagem, percebemos que essa mulher, cujo nome não conhecemos e cuja voz não ouvimos, é a representação da negra amável, doadora, ativa nos assuntos concernentes às atividades domésticas, mas totalmente passiva no que diz respeito à sua própria vida e vontades. Essa imagem está cristalizada no imaginário brasileiro pela figura da Tia Anastácia, famosa empregada do Sítio do Pica-Pau Amarelo, história baseada nos escritos de Monteiro Lobato e que foi adaptada para a televisão em diversos momentos no último século.

Também é interessante observar no excerto que o homem é apresentado como um sujeito contemplativo, cuja função é somente observar todas as ações da esposa, que vão desde as atividades burocráticas até os trabalhos relativos à limpeza do hotel. A posição de superioridade desse personagem masculino, que está sentado em sua poltrona, posição que o coloca como rei e senhor a observar sua serva a cumprir-lhe os desejos, evidencia a condição de subserviência da mulher, descrita praticamente como um objeto que faz todas as suas "obrigações" e parece aceitar a sua posição de bom grado, já que ela é observada e exposta pelos olhos do macho narrador.

O erotismo da mulher negra, característica recorrente na literatura e na mídia em geral, é o aspecto central do segundo estereótipo ao qual nos dedicaremos neste trabalho. Ao relatar um dos motivos que influenciam a sua viagem, Nart utiliza-se de um relato produzido anteriormente por um de seus irmãos, Pablo, que fora contratado anos

\footnotetext{
2 "Nos habíamos alojado en el hotel Djamila. Sus propietarios eran una amable y servicial negra gordísima, casada con un brasileño-palestino cuya actividad se reducía a contemplar sus dominios desde un sillón en recepción, dejando las ingratas tareas de gestión a cargo de su activísima esposa: recepcionista, cocinera, camarera, limpiadora, etc., todo en uno" (NART, 2002, p. 23).
} 
antes por uma agência da Organização das Nações Unidas (ONU) para analisar porcos na Bolívia e partiu para o Brasil logo após o término do trabalho.

Assim, meu irmão Pablo, mochila no ombro e esperança na alma, decidiu trocar os porcos bolivianos pelo mítico e esplendoroso biótopo de mulatas que qualquer espanhol que se preze associa de maneira automática com o país-continente que é o Brasil ${ }^{3}$ (NART, 2002, p. 11).

Podemos perceber que a volúpia e sensualidade, apresentada como característica natural, quase biológica, é frequente na mídia que atinge todo o mundo, formando essa figura erotizada arquetípica de toda descendência africana. A mulher negra, além de objetificada, é animalizada no momento em que é feita a comparação com os porcos. Sob outro olhar, percebemos o território boliviano como um local propício para a criação mamíferos da ordem dos suínos, enquanto o biótopo brasileiro proporciona o nascimento dessas mulheres negras voluptuosas, questão que indica propensão do narrador em apresentar o Brasil como um ambiente natural para o surgimento de seres humanos com essas características e a sua visão parcial da realidade, promovendo, por esse motivo, a produção de estereótipos justificados por uma posição distorcida da ciência:

\begin{abstract}
A intensidade subia tanto em sonoridade como em velocidade, incrementado com o frenesi de timbaleiros e dançantes. De mulheres, de meninas. Garotas preciosas e gordas apoteóticas, todas elas detentoras de graça de agilidade, proprietárias instintivas dessa capacidade que possuem os africanos ou os seus descendentes para adaptar ombros, quadris, pernas e braços à música, ao ambiente, e que carecemos em outras latitudes ${ }^{4}$ (NART, 2002, p. 294).
\end{abstract}

Essas negras detentoras de poderes mágicos de atração parecem viver e centrarse no corpo e da sexualidade. O caráter generalizante das descrições transforma a mulher negra em seres animalizados, hipersensualizados e sexualizados, fazendo com que elas sejam consideradas objetos destinados à contemplação e com função específica para $o$ trabalho, essencialmente por não se adequarem ao modelo branco instituído como natural e modelar. Todas as imagens construídas, desde a personagem extremamente trabalhadora e ativa até a mulher voluptuosa, reforçam a objetificação dessas mulheres que são vistas como utilitárias pelo viajante macho-europeu-colonizador.

O racismo está enraizado na cultura brasileira e também no imaginário europeu, problema que tem origem histórica, uma vez que a população negra sofreu durante todo o processo de colonização e pós-colonização com as sequenciais forças de dominação social, econômica e cultural pelas elites brancas europeias e os seus descendentes.

O preconceito em virtude da raça está baseado no processo de aquisição ideológica promovida por diversas instituições, que vão desde a escola até os meios de

\footnotetext{
3 “Así, mi Hermano Pablo, mochila al hombro y esperanza en el alma, decidió cambiar los gorrinos bolivianos por el mítico y esplendoroso biotopo de mulatas que cualquier españolito que se precie asocia de manera automática con el país-continente que es Brasil" (NART, 2002, p. 11).

4 "La intensidad subía tanto en sonoridad como en velocidad, incrementando el frenesí de timbaleros y danzantes. De mujeres, de niñas. Preciosas muchachas y gordas apoteósicas, todas ellas gráciles y ágiles, propietarias instintivas de esa capacidad que poseen los africanos o sus descendientes para adaptar hombros, caderas, piernas y brazos a la música, al baile, y de la que carecemos en otras latitudes" (NART, 2002, p. 294).
} 
comunicação em massa, passando, evidentemente, pela literatura. Necessário enfatizar que essas instituições ideológicas atingem os brasileiros e também a população negra brasileira. De acordo com van Dijk (2008), o discurso racista é construído geralmente por meio da mais ampla variedade de eventos comunicativos e atinge todas as camadas da sociedade, fazendo com que a reprodução dessas imagens seja naturalizada:

\begin{abstract}
A maior parte do que os grupos dominantes brancos "sabem" ou acreditam sobre a etnia dos Outros foi, portanto, formulada, mais ou menos explicitamente, em inúmeras conversações, histórias, reportagens de jornais, livros didáticos e discurso político. É também sobre essa base que as pessoas formam suas próprias opiniões e atitudes, e, a menos que haja boas razões para desviar do consenso do grupo, a maior parte dos membros reproduzirá o status quo étnico e adquirirá as ideologias dominantes que os legitime (VAN DIJK, 2008, p. 15).
\end{abstract}

O discurso racista promovido pela elite branca colonizadora é apresentado como norma e reproduzido muitas vezes pelos próprios grupos dominados. Nossa intenção ao discutir as imagens construídas a partir do discurso dominante e reproduzida pelos grupos dominados é que, mesmo se utilizando de mecanismos subjetivos e sutis, dentro de uma nação supostamente multicultural, o racismo é latente e precisa ser desconstruído. Os estereótipos, que visam categorizar, diminuir, inferiorizar algum grupo social, devem ser contestados e afastados na produção da imagem e da identidade nacional.

\title{
Considerações Finais
}

O pensamento é desenvolvido a partir da capacidade de abstração de um indivíduo inserido em um meio social específico. Nesse sentido, construímos nosso arquivo no contato com o "outro", na relação com o mundo. Em consequência da experiência adquirida nesse processo, reunimos no nosso imaginário várias realidades distintas que sobrecarregam a nossa memória e, para aliviar o seu trabalho, precisamos produzir imagens simplificadas, ou seja, criar generalizações.

A generalização pode ser definida como uma operação que aplica a um número indeterminado de pessoas as características compartilhadas por um grupo, evidenciando a falta de capacidade do ser humano em compreender as diferenças que coexistem em uma mesma sociedade. Esses mecanismos que formatam o imaginário de um povo e a forma como ele recria a imagem do "outro" é complexo e, por esse motivo, nos deparamos constantemente com estereótipos baseados em preconceitos explicáveis por fatores históricos, sociais e reforçados pela mídia e por uma elite com pensamento colonizador. Porém, é indiscutível que tais estratégias são utilizadas com uma finalidade específica: a manutenção do poder colonial.

$\mathrm{Na}$ obra estudada, pudemos observar que mesmo com a tentativa de construir uma análise coerente e verossímil de Brasil, Javier Nart não consegue se desprender dos estereótipos difundidos pelas diversas instituições de dominação e da sua própria gênese colonizadora. Um viajante que explora o corpo feminino e se acha no direito de falar por elas, dizeres que ressoam na sociedade, muito por causa da sua representação política e por fazer parte de uma classe hegemônica e dominante. Além disso, essas características fazem com que ele se ache no direito de usufruir da sua posição privilegiada e possuir, quer literal ou metaforicamente, do corpo da mulher brasileira. 
Resta-nos observar que o Brasil é um país onde reina a diversidade e a identidade brasileira pode ser traduzida a partir de aspectos da sua tradição e de elementos estrangeiros, adquiridos através do contato com diferentes realidades e em diferentes contextos. Falar de forma genérica das mulheres, das mulheres brasileiras e das mulheres brasileiras negras, é algo definitivamente impossível, assim como é impossível elencar todos os estereótipos construídos pelos estrangeiros. Por esse motivo, nosso objetivo com este trabalho foi discutir questões relacionadas a uma obra específica e fazer refletir sobre os preconceitos que a sociedade ainda apresenta de forma aparente ou velada, buscando repensar os estereótipos de mulher apresentada como peça útil para ser observada, admirada e possuída.

Essa aproximação dos estudos literários com as questões sociais é importante porque representa um método reflexivo para a compreensão de fenômenos políticos e dos seus objetivos. Esse processo subjetivo, essa reflexão intelectual mais aprofundada, proporciona uma produção que movimenta os poderes, de modo a pressionar uma mudança das práticas cotidianas que reproduzem discursos históricos e politicamente construídos para inferiorizar uma camada substancial da sociedade. Tratar dos estereótipos difundidos por instituições hegemônicas ainda significa um exercício pleno de desobediência, uma vez que surge como um método de libertação colonial, em seus mais diversos tipos e níveis.

Compreendendo a necessidade de avançar nas fronteiras do conhecimento sobre o ser humano, precisamos ressaltar a importância das ciências em um momento de tantas perdas na área. É necessário afirmar que essas produções se vinculam diretamente às necessidades de sobrevivência do ser humano em seus aspectos sociais, econômicos, culturais e artísticos. Um país alijado dos avanços científicos se mantém subalterno em relação a outros coletivos detentores de poder. Por esse motivo, é necessário que haja investimento em educação e financiamento em diversas áreas da pesquisa, proporcionando, então, o desenvolvimento de uma sociedade que depende dessa busca constante pela apropriação do saber.

\section{Referências}

AHMAD, A. Linhagens do presente. São Paulo: Boitempo, 2002.

BHABHA, H. A questão do "outro": diferença, discriminação e o discurso do colonialismo. In: Pós-modernismo e política, Rio de Janeiro: Rocco, 1991.

BONNICI, T. Conceitos-chave da teoria pós-colonial. Maringá: Eduem 2005.

BONNICI, T. Teoria e crítica literária feminista: conceitos e tendências. Maringá: Eduem 2007.

CARRIZO RUEDA, S. A. Construcción y recepción de fragmentos de mundo. In: CARRIZO RUEDA, S. A. (ed.) Escrituras del viaje. Buenos Aires: Biblos, 2008.

CORDEIRO, L. H. dos S. Representações de identidade e resistência pós-colonial em A Resposta (2015) de Kathryn Stockett. 2017. 153f. Dissertação (Mestrado em Letras) Universidade Estadual de Maringá, Maringá. 
MUNHOZ, R. F. O viajante e sua bagagem: imagens do Brasil e dos brasileiros (re)produzidas por dois espanhóis no início do novo milênio. 2019. 118 f. Dissertação (Mestrado em Letras) - Universidade Estadual de Maringá, Maringá, 2019.

NART, J. Viaje al otro Brasil: Del Mato Grosso a la Amazonia y al Nordeste Atlántico. Madrid: Punto de lectura, 2002.

PRATT, M. L. Os olhos do império. Bauru: USC, 1999.

SAID, E. Orientalismo: O Oriente como invenção do Ocidente. São Paulo: Companhia das Letras, 2007.

SILVA, P. V. B. da; ROSEMBERG, F. Brasil: Lugares de Negros e Brancos na Mídia. In: VAN DIJK, T. A. (org.). Racismo e Discurso na América Latina. São Paulo: Contexto, 2012.

SOUZA, C. H. M. R. de. Do cá e do lá: introdução à imagologia. São Paulo: Associação Editorial Humanitas, 2004.

VAN DIJK, T. A. (org.). Racismo e discursos na América Latina. Ed. ContextoUnesco-Brasil, 2008.

Recebido em 29 de maio de 2020

Aceito em 16 de agosto de 2020 